\title{
DIAGNOSTIC SIGNIFICANCE OF CLINICOPATHOLOGICAL CONCORDANCE IN VARIOUS SPECTRUMS OF SKIN DISORDERS
}

\author{
Kafle $S U^{1^{*}}$, Chaudhary $D^{2}$ Yamu $S^{2}{ }^{2}$ Jha $K^{2}$
}

\begin{abstract}
Affiliation
1. Associate Professor, Department of Pathology, Birat Medical College and Teaching Hospital

2. Lecturer, Department of Dermatology and Venereology and Leprology, Birat Medical College and Teaching Hospital
\end{abstract}

\section{ARTICLE INFO}

Received : 05 February, 2020

Accepted : 27 March, 2020

Published : 30 June, 2020

C Authors retain copyright and grant the journal right of first publication with the work simultaneously licensed under Creative Commons Attribution License CC - BY 4.0 that allows others to share the work with an acknowledgment of the work's authorship and initial publication in this journal.

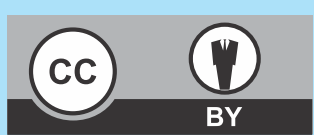

ORA 164

DOI: https://doi.org/10.3126/bjhs.v5i1.29633

\author{
* Corresponding Author \\ Dr. Santosh Upadhyaya Kafle \\ Associate Professor \\ Department of Pathology \\ Birat Medical College and Teaching Hospital \\ Email:drsantoshkafle@gmail.com \\ ORCID ID: https://orcid.org/0000-0002-7743-0485
}

\section{Citation}

Kafle SU, Chaudhary D, Yamu S, Jha K. Diagnostic Significance of Clinicopathological Concordance in Various Spectrums of Skin Disorders BJHS 2020;5(1)11:955-959. w

\section{ABSTRACT}

\section{Introduction}

Wide spectrums of skin disorders exist in the world. Skin biopsy is a proven method for allying the dermatologist in overcoming the diagnostic dilemmas that occur in consultations. The different level of clinicopathological concordance, either full or partial and discordant study may reflect the agreement between the clinicians and pathologists for diagnosing spectrum of skin disorders.

\section{Objectives}

To analyze the histopathological spectrum of skin diseases emphasizing on the diagnostic significance of its clinicopathological concordance.

\section{Methodology}

This is a prospective cross sectional hospital based study of skin biopsies obtained in the Department of Pathology, at Birat Medical College and Teaching Hospital from Dec 2016 to Jan 2020. Demographic data, nature of lesions, correlation between clinicopathological concordance and histopathological diagnosis were analyzed using SPSS version 16.

\section{Result}

Among 111 skin biopsies, female gender of 19-39 years age groups was predominant. The commonest histopathological diagnosis of skin biopsies was under infectious and bacterial origin category (24.3\%) reflecting non-neoplastic nature mostly. The overall clinicopathological concordant was $78.38 \%$ (fully concordant $27.93 \%$ and partially concordant $50.45 \%$ ) and discordant $21.62 \%$. Nature of lesions was strongly correlated $(p<0.05)$ with age group, while it was weak with gender. However, the relationship was very strong between histopathological diagnosis and clinicopathological concordance $(p<0.05 \%)$.

\section{Conclusion}

Findings suggest that the clinicopathological concordance correlated well in histopathologically diagnosed disease category of skin disorders. This reflects the high diagnostic value of histopathological examinations for diagnosing different spectrum of skin disorders.

\section{KEYWORDS}

Clinicopathological concordant, diagnostic dilemmas, discordant, skin disorders. 


\section{INTRODUCTION}

Skin being the largest organ of the human body, acts as a barrier to the different environmental factors. However, it is involved in a wide spectrum of disorders ranging from inflammatory conditions to neoplastic lesions. ${ }^{1}$ Majority of the skin disorders can be diagnosed by history, clinical presentation and biochemical investigations. Among which, around $1.3 \%$ of patients attending the dermatology clinic need a skin biopsy. ${ }^{2}$ Hence, histopathological examination still remains gold standard for helping the dermatologist in overcoming diagnostic dilemma. ${ }^{3}$

For this, both the clinical and histopathological data correlating each other offers substantial clues in arriving at the accurate diagnosis. ${ }^{4}$ Likewise, exact anatomical location, duration and number of the lesions with other related conditions super add the information in confirming the diagnosis. ${ }^{5}$ Such clinical information incorporation during evaluation together with clinical knowledge for histopathological examinations is important to achieve accurate and prompt diagnosis. At this point, it becomes even mandatory for complete and orderly communication to exist between the clinician and the pathologist, particularly when the pathology requisition forms are completed. Some of the studies have examined the clinico-pathological concordance or agreement rate for proper diagnosis of numerous skin disorders, despite of critical clinical and histopathological data. ${ }^{2,3}$

The different level of clinicopathological concordance, either full or partial and discordant may reflect the agreement between the clinicians and pathologists for diagnosing spectrum of skin disorders. Hence, such concordance in evaluating the different spectrum of skin lesions seems to have great diagnostic significance. We hypothesized that such kind of clinicopathological concordance or agreement in our institute seems to be strong. Moreover, such study hasnot been carried out locally in our country.

Hence, this study is designed to analyze the histopathological spectrum of skin diseases emphasizing on the diagnostic significance of its clinicopathological concordance.

\section{METHODOLOGY}

This is a prospective, hospital based cross-sectional study carried out in the Department of Pathology, Birat Medical College and Teaching Hospital (BMCTH), Morang, Nepal commencing from December 2016 to January 2020, after receiving the institutional permission. This study included all the skin biopsies received in the collection unit of histopathology section of Department of Pathology, BMCTH irrespective of age and gender during the study period.

As per our departmental norms, specimens were fixed in $10 \%$ formalin solution. Necessary information related to detailed clinical history and previous biopsies if done any were taken into consideration from the histopathology requisition forms received including the clinical provisional and differential diagnosis. Gross examination of the sample for its size, shape, color and consistency was done. Representative areas or entire tissue of skin biopsies were sectioned and processed in an automated tissue processor for an overnight schedule of 16-18 hours. Paraffin blocks were made, trimmed the tissue sections of 5-7 $\mathrm{mm}$ cut and floated in a water bath at $45^{\circ} \mathrm{C}$ and then taken on albuminized slides. The slides were then examined under a light microscope after hematoxylin and eosin stain. Also, special stain: Periodic acid-Schiff (PAS) and Zeihl-Neelsen (ZN) were used when required.

The diagnostic histopathological spectrum of the skin diseases has been categorized as: infectious: bacterial, viral, fungal origin, eczematous, noninfectious papulosquamous disorder, vesiculobullous disorder, inflammatory disorder, pigment disorder, degenerative disorder, mesenchymal disorder, vasoproliferative disorder, photodermatoses, vasculitis, descriptive reports, benign neoplasm and malignant neoplasm. ${ }^{6}$ The main study outcome is clinicopathological concordance, which included three groups as: fully concordant, partially concordant and discordant. Fully concordant has been defined as identical provisional clinical and histopathological diagnosis. Partially concordant has been defined as inclusion of the histopathological diagnosis as one of the clinical diagnosis and the differential diagnosis recorded by the dermatologist. The overall or total concordant has been defined as both combined fully and partially concordant. Discordant has been defined as incompatibility between the histopathological diagnosis and both the provisional clinical diagnosis and the differential diagnosis. ${ }^{\text {? }}$

Sample size required for the study was calculated by the following formula:

Sample size $(n)=z^{2} \times(p q) / e^{2}=1.96 \times 1.96 \times 0.5(1-0.5) / 0.1^{2}=96$ where, $\mathrm{z}=1.96$ at $95 \% \mathrm{Cl}$

$p=$ prevalence proportion in target population to have certain character

$q=(1-p)$

$\mathrm{e}=$ allowable error

The minimum sample size calculated was 96 . Non-random sampling has been done, so $15 \%$ sample was added. Thus, the final sample size taken was 111 . The chi-square test is used to test for significant differences in clinicopathological concordance in relation to the different characteristics of the study biopsies and histopathological diagnosis. A p-value $<0.05$ was considered significant. Data was entered in Microsoft Excel and analyzed in SPSS version 16.

\section{RESULTS}

Among one hundred and eleven skin biopsies recruited in our study, female populations were predominant over male with the highest frequency in the second to fourth decade of life. (Table 1). 


Table 1: Social demographics of the study biopsies
\begin{tabular}{|c|c|}
\hline Age Group (years) & Frequency $\mathbf{n}(\%)$ \\
\hline $0-18$ & $11(9.90)$ \\
\hline $19-39$ & $56(50.45)$ \\
\hline $40-59$ & $31(27.92)$ \\
\hline 60 and above & $13(11.71)$ \\
\hline Gender & Frequency $\mathbf{n}(\%)$ \\
\hline Male & $45(40.55)$ \\
\hline Female & $66(59.45)$ \\
\hline
\end{tabular}

The most common histopathological diagnosis of skin biopsies was of bacterial origin (24.3\%) under the infectious category and the rare histopathological diagnosis was under mesenchymal, photodermatoses, vasoproliferative and vesiculobullous disorder, each comprising $0.1 \%$ respectively. (Table 2)

Table 2: Categorization of skin disease as per histopathological
diagnosis
\begin{tabular}{|l|c|}
\hline \multicolumn{1}{|c|}{ Disease categorization } & Frequency n (\%) \\
\hline Benign neoplasm & $11(9.90)$ \\
\hline Degenerative disorder & $4(3.60)$ \\
\hline Descriptive report & $8(7.20)$ \\
\hline Eczematous & $4(3.60)$ \\
\hline Infectious: Bacterial & $27(24.32)$ \\
\hline \multicolumn{1}{|c|}{ Fungal } & $2(1.80)$ \\
\hline Viral & $2(1.80)$ \\
\hline Inflammatory disorder & $15(13.51)$ \\
\hline Malignant neoplasm & $5(4.50)$ \\
\hline Mesenchymal disorder & $1(0.90)$ \\
\hline Noninfectious papulosquamous disorder & $20(18.01)$ \\
\hline Photodermatoses & $1(0.90)$ \\
\hline Pigment disorder & $7(6.30)$ \\
\hline Vasculitis & $2(1.80)$ \\
\hline Vasoproliferative disorder & $1(0.90)$ \\
\hline Vesiculobullous disorder & $1(0.90)$ \\
\hline
\end{tabular}

After evaluating all the recruited skin biopsies, the commonest histopathological nature of diagnosed specimen was of non-neoplastic origin (88.3\%). Among all of the study biopsies, clinicopathological concordant (total) was found more than discordant. Of which, the partially concordant (50.5\%) outnumbered the full concordant. (Table 3 )
Table 3: Distribution of nature and clinicopathological concordance of skin biopsies

\begin{tabular}{|l|c|l|c|}
\hline \multicolumn{1}{|c|}{$\begin{array}{c}\text { Nature of the } \\
\text { lesion }\end{array}$} & $\begin{array}{c}\text { Frequency } \\
\mathbf{n ( \% )}\end{array}$ & $\begin{array}{c}\text { Clinicopathological } \\
\text { Concordance }\end{array}$ & $\begin{array}{c}\text { Frequency } \\
\mathbf{n ( \% )}\end{array}$ \\
\hline Benign & $8(7.21)$ & $\begin{array}{l}\text { Fully concordant } \\
\text { Partially concordant }\end{array}$ & $\begin{array}{c}31(27.93) \\
56(50.45)\end{array}$ \\
Malignant & $5(4.51)$ & Concordant (Total) & $87(78.38)$ \\
\hline Non-neoplastic & $98(88.28)$ & Discordant & $24(21.62)$ \\
\hline
\end{tabular}

The histopathological diagnosis in the study was categorized individually as benign, malignant and non-neoplastic variables for defining the nature of lesions. The correlation between the natures of such diagnosed skin lesions with different age groups revealed strong positive correlation, $p$-value $<0.001$. However, there was no significant correlation value between the natures of such lesions with gender involved in the study, p-value 0.151. (Table 4)

Table 4: Cross tabulation between age groups, gender and nature of skin biopsies (using Pearson's chi-square tests)

\begin{tabular}{|c|c|c|c|c|c|c|c|c|}
\hline \multirow[t]{2}{*}{ Nature of lesion } & \multicolumn{4}{|c|}{ Age groups (years) } & \multirow{2}{*}{ p-value } & \multicolumn{2}{|c|}{ Gender } & \multirow{2}{*}{ p-value } \\
\hline & $0-18$ & $19-39$ & 40-59 & 60-above & & Male $n(\%)$ & \begin{tabular}{|c|}
$\begin{array}{c}\text { Female } \\
\mathrm{n}(\%)\end{array}$ \\
\end{tabular} & \\
\hline Benign $n(\%)$ & $0(0)$ & $5(8.90)$ & $1(3.20)$ & $2(15.40)$ & \multirow{4}{*}{$0.008^{*}$} & $4(8.90)$ & $4(6.10)$ & \multirow{4}{*}{0.151} \\
\hline Malignant $n(\%)$ & $0(0)$ & $0(0)$ & $2(6.50)$ & $3(23.10)$ & & $0(0)$ & $5(7.60)$ & \\
\hline $\begin{array}{l}\text { Non-neoplastic } \\
\mathrm{n}(\%)\end{array}$ & $11(100)$ & $51(91.10)$ & $28(90.30)$ & $8(61.50)$ & & $41(91.10)$ & $57(86.40)$ & \\
\hline Total & $11(100)$ & $56(100)$ & 31(100) & $13(100)$ & & $45(100)$ & $66(100)$ & \\
\hline
\end{tabular}

*the test result is significant at $p<0.05$

The correlation between the categorization of histopathological diagnosis and clinicopathological concordance revealed strong positive correlation, $p$-value $<0.05$. Among the different histopathological diagnoses, the infectious disease of bacterial origin $27(100 \%)$ and the descriptive report $8(100 \%)$ category were highest among the total concordant and discordant respectively. (Table 5)

Table 5: Cross tabulation between categorization of histopathological diagnosis and clinicopathological concordance of skin biopsies (using Pearson's chi-square tests)

\begin{tabular}{|c|c|c|c|c|}
\hline \multirow{2}{*}{$\begin{array}{l}\text { Categorization of } \\
\text { histopathological } \\
\text { diagnosis }\end{array}$} & \multicolumn{2}{|c|}{ Concordance } & \multirow{2}{*}{$\begin{array}{l}\text { Total } \\
\mathrm{n}(\%)\end{array}$} & \multirow[t]{2}{*}{ p-value } \\
\hline & $\begin{array}{l}\text { Total } \\
\text { Concordant } \\
\text { (fully and } \\
\text { partially) } n(\%)\end{array}$ & $\begin{array}{c}\text { Discordant } \\
n(\%)\end{array}$ & & \\
\hline Benign neoplasm & $8(72.73)$ & $3(27.27)$ & $11(100)$ & \\
\hline Degenerative disorder & $4(100)$ & $0(0)$ & $4(100)$ & \\
\hline Descriptive report & $0(0)$ & $8(100)$ & $8(100)$ & \\
\hline Eczematous & $3(75)$ & $1(25)$ & $4(100)$ & \\
\hline Infectious: Bacterial & $27(100)$ & $0(0)$ & $27(100)$ & \\
\hline Infectious: Fungal & $1(50)$ & $1(50)$ & $2(100)$ & $0.001^{*}$ \\
\hline Infectious: Viral & $1(50)$ & $1(50)$ & $2(100)$ & \\
\hline Inflammatory disorder & $11(73.3)$ & $4(26.7)$ & $15(100)$ & \\
\hline Malignant neoplasm & $3(60)$ & $2(40)$ & $5(100)$ & \\
\hline Mesenchymal disorder & $0(0)$ & $1(00)^{\prime}$ & $1(100)$ & \\
\hline $\begin{array}{l}\text { Noninfectious } \\
\text { papulosquamous disorder }\end{array}$ & 19(95) & $1(5)$ & $20(100)$ & \\
\hline Photodermatoses & $1(100)$ & $0(0)$ & $1(100)$ & \\
\hline Pigment disorder & $7(100)$ & $0(0)$ & $7(100)$ & \\
\hline Vasculitis & $2(100)$ & $0(0)$ & $2(100)$ & \\
\hline Vasoproliferative disorder & $0(0)$ & $1(100)$ & $1(100)$ & \\
\hline Vesiculobullous disorders & $0(0)$ & $1(100)$ & $1(100)$ & \\
\hline Total & $87(78.37)$ & $24(21.63)$ & $111(100)$ & \\
\hline
\end{tabular}

*the test result is significant at $p<0.05$ 


\section{DISCUSSION}

The skin disorders are heterogeneous with a wide clinical and histopathological spectrum. These lesions are common in both males and females. ${ }^{8}$ In our study of 111 skin biopsies, female patients outnumbered male patients, as females were 66 and male 45 in numbers. The most common age group was between 19-39 years followed by 40-59 years respectively. The least number of biopsy was seen among the pediatric and early adolescent age group (0-18 years). Though biopsy is important for diagnosis of dermatological diseases in pediatric age group, but its difficult to have biopsy done in such pediatric age group patients incomparison to adults. So, there were few biopsies received of pediatric age group in this study. This findings was different when compared with the study conducted by Gupta P et $\mathrm{al}^{6}$, Mamatha K et al ${ }^{9}$ and Grover et al. ${ }^{10}$ The findings in the study of Gupta P et $\mathrm{al}^{6}$ showed the male patients being out numbered females in their 253 skin biopsies. The most common age group was between $31-40$ years and the least affected was between 0-10 years. In Mamatha $\mathrm{K}$ et al ${ }^{9}$ study, a total of 286 cases were included, out of which 136 cases were male and 150 were female, but the maximum number of cases belonged to 51-60 years of age. Likewise, Grover et $\mathrm{al}^{11}$ also yielded the predominance of male gender within the 11-20 years of age group in their study.

All of the skin biopsies diagnosed by histopathological examination in our study has been categorized under as: benign neoplasm, degenerative disorder, descriptive report, eczematous, infectious: of bacterial, fungal and viral origin, inflammatory disorder, malignant neoplasm, mesenchymal disorder, non infectious papulosquamous disorder, photodermatoses, pigment disorder, vasculitis, vasoproliferative disorder and vesiculobullous disorder. Among which, the highest frequency was seen for infectious category of bacterial origin $27(24.3 \%)$, followed by noninfectious papulosquamous disorder $20(18 \%)$ and inflammatory disorder $15(13.5 \%)$ respectively. Likewise, mesenchymal disorder, photodermatoses, vasoproliferative and vesiculobullous disorder resulted among the least number, each of $1(0.9 \%)$ cases respectively (Table 2$)$. Within the infectious category of bacterial origin, the leprosy was the most common lesion. We used special stain: Ziehl-Neelsen (ZN) to demonstrate the organism. In the study conducted by Gupta P et al $^{6}$, the broad spectrum of histopathological diagnosis was almost similar to our study result revealing the infectious disorders of bacterial origin being the most common one. Likewise, in the study conducted by Al-Saif FM et $\mathrm{al}^{7}$ the most common histopathological diagnosis was under papulosquamous and eczematous dermatoses followed by benign neoplasm, pigmentary diseases and others respectively. Unlike in our study, the infectious diseases category in theirs study was not under the most common category.

The skin disorders in our study are categorized under different histopathological diagnosis. Such diseases are further distributed per their nature revealing the predominant lesion as non-neoplastic of $98(88.3 \%)$ cases followed by benign of $8(7.2 \%)$ and malignant $5(4.5 \%)$ cases in nature respectively (Table 3$)$. We had a strong correlation, $p$-value $<0.05$ comparing between the nature of such histopathologically diagnosed lesions and related age groups. However, there was no significant correlation yield between the natures of such histopathologically diagnosed lesions with the gender involved in the study (Table 4).Some of the study has been observed performing to assess the diagnostic accuracy of certain skin diseases for comparing the clinical to the histopathological diagnosis. One of these studies found $3034(76.8 \%)$ biopsies of pathological diagnosis to be consistent with the clinical diagnosis, and inconsistent in 915(23.3\%) biopsies report. ${ }^{11}$ The clinicopathological consistency was higher in patients with adequate clinical descriptive information in all skin disorders included in their study. Likewise, in a study of 371 cases conducted by Sa DK et $\mathrm{al}^{2}$ revealed $250(67.4 \%)$ cases of histopathological diagnosis consistent with provisional diagnosis, 71(19.1\%) cases were corroborative with one of the differential diagnosis and $50(13.5 \%)$ cases were inconsistent with the clinical diagnosis provided.

Our study revealed the clinicopathological concordance frequency more for total concordant as $87(78.38 \%)$ cases and only $24(21.6 \%)$ cases being discordant. Among the total concordant cases, fully and partially concordant cases were $31(27.93 \%)$ and $56(50.45 \%)$ respectively. This high yielding rate of total clinicopathological concordant and minimum discordant cases in our study reflects the detailed clinical information shared, well representative adequate biopsy received and accurate histopathological diagnosis yield. Some of the studies reflects that the diagnostic accuracy for such biopsy depends upon numbers of factors like as choice of lesion, choice of biopsy site, technique of biopsy, properment of history and clinical diagnosis in biopsy requisition form, proper tissue fixation with staining and adequate coordination between dermatologist and pathologist. ${ }^{12-14}$ Likewise, a study conducted by Bin Yap et al found $92 \%$ clinicopathological consistency. This high success rate was explained as being attributed to close cooperation between the dermatologist and pathologist. ${ }^{14}$

The clinicopathological concordance result of our study is generally comparable with similar kinds of studies revealing the concordance ranged between $67 \%$ and $87 \%$. $^{2,3,11,15}$ Likewise, studies from Turkey ${ }^{11}$ and Greece ${ }^{3}$ showed that the pathological diagnoses were concordant with clinical diagnosis in $76.8 \%$ and $68 \%$ of the cases respectively. Moreover, a review of 371-skin biopsies study in India resulted in $67.4 \%, 19.1 \%$ and $13.5 \%$ cases as full concordant, partial concordant and discordant respectively. ${ }^{2}$ Similarly, a large sample study (4268 skin biopsies) evaluation in Saudi Arabia showed $28.3 \%$ cases as fully concordant, $47.6 \%$ partially concordant and $24.1 \%$ as discordant, which seems alike with our study outcomes and findings. ${ }^{7}$ In addition, our study revealed a strong correlation, $\mathrm{p}$-value $<0.05$ yield between the categorization of histopathological diagnosis and its clinicopathological concordance (Table 5). This proves that the relation between clinician as dermatologist and pathologist along with the several other factors like knowledge about precise site from where biopsy is to be done, proper timing, correct techniques, storage and transportation medium also affects the rate of clinicopathological concordance. One of the studies showed the diagnostic yield of clinician as non-dermatologists between $34 \%$ to $45 \%$ (more discordant rate) and that of the 
clinician as dermatologists being high as $71 \%$ to $75 \%$ (less discordant rate). ${ }^{15}$ Therefore declining such discordant rate dependupon the minimization of factors as inappropriate choice of the lesion, poorly executed biopsies techniques, irrelevant clinical diagnosis with insufficient clinical information, faultytissue fixation with processing and inappropriate staining methods. ${ }^{16-18}$

These findings thus add up the importance of histopathological perspective to be both helpful and reliable in the majority of cases in our study with adequate cooperation between the dermatologist and dermatopathologist.

\section{CONCLUSION}

Our findings reveal positive correlation between the histopathological diagnosis and its clinicopathological concordance among various skin lesions, majority being total concordant. Non-neoplastic nature of the skin lesions was seen predominantly and bacterial origin of infectious type was highest among histopathological disease category. Strong positive correlation was observed between natures of histopathologically diagnosed skin lesions and the patient's age group but weak correlation existed with gender. This study thus reflects the clinicians to enlighten the accurate diagnosis of skin diseases that would likely benefit from biopsy requests.

\section{REFERENCES}

1. Gaikwad SL, Kumawat UD, Sakhare NA, D'costa GF. Histopathological Spectrum of Skin Lesions- Experience at Rural Based Hospital. Int J cur Res.2016 Aug;8(8):36223-7. Available online at http:// www.journalcra.com

2. Sa DK, Kumar P. Clinicopathological consistency in diagnosis of skin disorders: a retrospective study of 371 histopathology reports. JPAD 2016; 26: 96-8.DOI: 10.5144/0256-4947.2019.388

3. Kortifis C, Gregoriou S, Antoniou C, Katsambas AD, Rigopoulos D. "Skin biopsy in the context of dermatological diagnosis: A retrospective cohort study". DermatolResPract.2014;2014:734906. DOI: $10.1155 / 2014 / 734906$

4. Narang S, Jain R. An evaluation of histopathological findings of skin biopsies in various skin disorders. APALM. 2015 Jan-Mar;2(1):A42-6. https://www.pacificejournals.com/journal/index.php/apalm/article /view/65/pdf_48

5. Mehar R, Jain R, Kulkarni CV, Narang S, Meena M, Patidar H. Histopathological study of dermatological lesions- A retrospective approach. Int J Med Sci Public Health. 2014;3:1082-5. DOI: 10.5455/ijmsph.2014.190620142

6. Gupta P, Karuna V, Grover K, Rathi M, Verma N. The histopathological spectrum of skin diseases with emphasis on clinicopathological correlation: A prospective study. IP Journal of Diagnostic Pathology and Oncology, April-June, 2018;3(2):91-95. DOI: 10.18231/25813706.2018.0020

7. Al-Saif FM, Binsufayan SA, Alhussain AH, Alkaff TM, Alshaikh HM, Aldosari MS, et al. Clinicopathological concordance in the diagnosis of skin diseases: a retrospective analysis of 5000 histopathology reports. Ann Saudi Med 2019; 39(6): 388-394. DOI: 10.5144/02564947.2019.388

8. Singh S, Debnath A, Datta D, Chakravarty S, Chaubey RN. Histopathological Evaluation of Skin Lesions with Special Reference to Skin Adnexal Tumors in a Tertiary Centre of North-Eastern India- A Three Year Study. IOSR-JDMS. 2016 Feb;15(2):34-9. DOI: 10.9790/085315223439

\section{RECOMMENDATIONS}

A larger sample size may yield more precise and accurate information on clinicopathological concordance in diagnosis of various skin disorders.

\section{LIMITATIONS OF THE STUDY}

Our study would have been more informative if we had observed the individual histopathologically diagnosed disease correlation for the clinicopathological concordance including the relation to different sites of biopsy and biopsy techniques.

\section{ACKNOWLEDGEMENTS}

We are thankful to Dr. Tara Kafle for her support in doing statistical analysis. We are also grateful to all the faculties and laboratory staff of the Department of Pathology of Birat Medical College and Teaching Hospital.

\section{CONFLICT OF INTEREST}

None

\section{FINANCIAL DISCLOSURE}

None

9. Mamatha K, S Susmitha, Vijayalaxmi S Patil, Sathyashree K V, Disha B S. Histopathological spectrum of dermatological lesions - An experience at tertiary care centre. IP Archives of Cytology and Histopathology Research, April-June, 2018;3(2):83-88. DOI: 10.18231/2456-9267.2018.0017

10. Grover S, Agale SV, D'costa GF, Valand AG, Gupta VK. Clinico-Histopathological Spectrum of Infectious Granulomatous Dermatoses in Western India-A Representative Study from Mumbai. J ClinDiagn Res. 2016 Apr;10(4):10-4. DOI: 10.7860/JCDR/2016/16459.7568

11. C. Aslan, F. G"oktay, A. T. Mansur, I. E. Ayding"oz, P. G"unes and T. R. Ekmekc,i, "Clinicopathological consistency in skin disorders: a retrospective study of 3949 pathological reports," Journal of the American Academy of Dermatology, vol. 66, no. 3, pp. 393-400, 2012. DOI: $10.1016 /$ j.jaad.2010.12.031

12. Khopkar U, Doshi B. Improving diagnostic yield of punch biopsies of the skin. Indian JDermatolVenereolLeprol. 2008;74 :527-31. DOI: 10.4103/0378-6323.44333

13. Sleiman $R$, Kurban $M, A b b a s ~ O$. Maximizing diagnostic outcomes of skin biopsy specimens. Int J Dermatol . 2013;52 :72-8. DOI: 10.1111/j.1365-4632.2012.05731

14. Bin Yap FB. Dermatopathology of 400 skin biopsies from Sarawak. Indian J DermatolVenereolLeprol. 2009;75 :518-9. DOI: 10.4103/03786323.55407

15. Sellheyer K, Bergfeld WF. A retrospective biopsy study of the clinical diagnostic accuracy of common skin diseases by different specialties compared with dermatology. J Am AcadDermatol 2005; 52: 823-3. DOI:10.1016/j.jaad.2004.11.072

16. U. Khopkar and B. Doshi, "Improving diagnostic yield of punch biopsies of the skin," Indian Journal ofDermatology, Venereology and Leprology, vol. 74, no. 5, pp. 527-531, 2008. DOI: 10.4103/0378-6323.44333

17. R. Sleiman, M. Kurban, and O. Abbas, "Maximizing diagnostic outcomes of skin biopsy specimens," International Journal of Dermatology, vol. 52, no. 1, pp. 72-78, 2013. DOI: 10.1111/j.1365-4632.2012.05731

18. E. Mclnnes, "Artefacts in histopathology," Comparative Clinical Pathology, vol. 13, no. 3, pp. 100-108, 2005. DOI: 10.1007/s00580004-0532-4 